\title{
Clinical Features of the Stroke Patients in Bangladesh
}

Dr. Mohammad Mahbubul Haque ${ }^{1 *}$, Dr. Raihan Rotap Khan², Dr. Mohammad Mushahidul Islam², Dr. Mohammad Shamsul Alam ${ }^{2}$

${ }^{1}$ Associate Professor, Department of Medicine, Sheikh Hasina Medical College, Jamalpur, Bangladesh
${ }^{2}$ Assistant Professor, Department of Medicine, Sheikh Hasina Medical College, Jamalpur, Bangladesh

DOI: $10.36347 /$ sasjm.2021.v07i03.003

| Received: 26.02.2021 | Accepted: 10.03.2021 | Published: 21.03.2021

*Corresponding author: Dr. Mohammad Mahbubul Haque

\section{Abstract}

Original Research Article

Background: Nearly three-quarters of all strokes occur in people over the age of 65.Although strokes can and do occur at any age, the risk of having a stroke more than doubles each decade after the age of 55 years. The aim of this study was to assess the clinical status of the stroke patients attended in a tertiary care hospital of Bangladesh. Methods: This descriptive cross sectional study was conducted at the department of Medicine in Sheikh Hasina Medical College and Hospital, Jamalpur, Bangladesh during the period from January 2018 to December 2018. Non randomized, purposive sampling technique was applied for this study. In total 180 stroke patients attended to the mentioned hospitaal were finalized as the sample and all the nurses engaged in the treatment procedure were associated in the study. Data was collected by using a semi structure, pre-tested and modified interviewer administered questionnaire. Statistical package for social science (SPSS) version 20.0 (Chicago) a computer programmed was used to entry and analyze the collected data. Result: Among the respondents $24.6 \%$ affected in right side, $23 \%$ left side and $20.2 \%$ both sides but $32.2 \%$ respondents could not get it diagnosed. In this study, majority of the respondents (95\%) family history of CVD was positive, and only 5\% family history of CVD was negative. In total $44.3 \%$ respondents very suffering from HTN for 1-2 years, followed by $33.9 \%, 18.6 \%$, and 3.3\% suffered for 3-5 years, 6-10 years, and more than 10 years respectively whereas $46.2 \%$ of the respondents very suffering from DM for 3-5 years, followed by $45.5 \%$ for $1-2$ years, and rest $8.3 \%$ for $6-10$ years. There was the association between gender and knowledge on risk factor of stroke is DM. The association is strongly significant where the p-value is 0.000 (which is less than .001). Conclusion: Stroke cases in Bangladesh have significantly increased in number over the past decades; adverse outcome from these cases are also rising due to the low number of neurologists and specialized hospitals in the country. Because stroke poses long-term economic impacts on individuals, families, and the country; study findings urge the government to put more emphasis on healthcare development by building more stroke rehabilitation units and tertiary hospitals to prevent stroke occurrence and recurrence.

Keywords: Clinical features, Stroke, CVD.

Copyright $(2021$ The Author(s): This is an open-access article distributed under the terms of the Creative Commons Attribution 4.0 International License (CC BY-NC 4.0) which permits unrestricted use, distribution, and reproduction in any medium for non-commercial use provided the original author and source are credited.

\section{INTRODUCTION}

Bangladesh is 84 th in mortality rate due to stroke, ranked by the World Health Organization (WHO). Approximately, (75\%) seventy-five percent of all strokes occur in people aged more than 65 years. Although strokes can and do occur at any age, the risk of having a stroke more than doubles each decade after the age of 55 years. Stroke is a life threatening severe medical condition come about if the blood supply to part of the brain is cut off. It is also recognized as Cerebrovascular Accident (CVA) as well as Cerebrovascular Insult (CVI) or brain attack as because poor blood stream to the brain causes cell death. Even though stroke is frequently observed in older patients, but evidence suggests that it also witnessed in the younger ones. Brain stem, cerebellum and cerebrum are the three main parts of human Brain. The brain stem controls many of the body's basic functions, including breathing, chewing, swallowing and eye movements. The major pathways from the cerebrum the thinking part of the brain also pass through the brain stem to the body. The cerebellum, attached to the back of the brain stem, coordinates movements and balance. A stroke is an intra-axial hemorrhagic; that is, it occurs within, rather than outside the brain tissue. The other type of intracranial hemorrhage is extra axial hemorrhage, like epidural, subdural and subarachnoid hematomas, which all befall inside the skull but outer of the brain tissue. There are two main kinds of intra axial hemorrhages: 
intra parenchymal hemorrhage and intra ventricular hemorrhages. For instance, with other categories of hemorrhages inside the skull, intra parenchymal bleeds are a severe health crisis as they can upsurge intracranial pressure, which if not treated properly then it may lead to coma and death. The mortality rate for intra parenchymal bleeds is above forty percent [1]. Intra cerebral hemorrhage are, accounting for $10 \%$ of hospital admissions for stroke seemed to be the most common neurologic admission and medical death that observed in other regions of the country and a little over one fifths of stroke patients die [2]. Stroke is a predominantly ischemic, accounted for $77.6 \%$ of the neurological case. Central nervous system infections, involving mostly of meningitis and tetanus, accounted for $6.6 \%$ and $3 \%$ of cases, correspondingly. The myelin pathies were the cause of neurologic admissions in $5.4 \%$ with paraplegia and quadriplegia resulting from myelopathies accounting for $5 \%$ and $0.4 \%$ of the cases [3]. Arterial blood flow to the brain transpires over four main arteries: two large internal carotids providing blood to the anterior portion of the brain and two smaller vertebral arteries providing blood to the posterior portion of the brain, brainstem and spinal cord. The two internal carotid arteries turn off the aortic arch and spread to the near of midbrain where they go into the circle of Willis. At this junction, the MCA and anterior cerebral arteries (ACA) turn off the internal carotid arteries. The MCA provides blood to lateral portions of the brain in the frontal (including the primary motor strip); parietal (including the primary sensory strip) and occipital lobes [3]. Arterial blood flow to the brain transpires over four main arteries: two huge internal carotids providing blood to the frontal part of the brain and two smaller vertebral arteries providing blood to the posterior portion of the brain, brainstem and spinal cord. The two internal carotid arteries branch off the aortic arch and extend to the level of midbrain where they enter the circle of Willis. The MCA and anterior cerebral arteries branch off the internal carotid arteries at junction. The MCA provides blood to lateral portions of the brain in the frontal (including the primary or strip): parietal (including the primary sensory strip) and occipital lobes. The and anterior cerebral artery (ACA) as provide blood to the medial portion of the brain, optic tract and sub cortical structures of the brain [4]. The anterior communicating artery connects two the two ACAs, allowing for bilateral blood flow in the presence of lesions to one ACA before the ACA-ACOMA junction. The two vertebral arteries unite at the level of the brainstem to form the basilar artery. The basilar artery continues up the brainstem before branching into two posterior communicating arteries (PCOMA), which form the posterior portion of the circle of Willis. The PCOMA arteries connect of the internal carotid arteries on either side, closing the circle of Willis. PCOMA arteries provide blood to the anterior vessels of the circle of Willis in the face of lesions to the internal carotid arteries [5]. The posterior cerebral arteries (PCA) branch off the basilar artery at the same junction as the PCOMAs and supply blood flow to the occipital lobe and portions of the temporal lobe. The venous system does not copycat arterial system design contrast to the other areas in the body. Deep veins and the Dural sinuses are accountable for the main stream of venous drainage; equally vacant into the core jugular veins. The exceptions a small amount of venous blood that drains through the ophthalmic and pterygoid venous plexuses into the emissary veins to the scalp and down the system of Para vertebral veins in the spinal canal [6]. Factors affecting of stroke are cerebral blood flow include arterial pressure, venous pressure, intracranial pressure, blood viscosity and the degree of active constriction or dilation of the cerebral arterioles. As the skull is not flexible and brain tissue and spinal fluid are fundamentally incompressible, the volume of blood, spinal fluid and brain in the skull at any single time must be relatively constant. Normal cranial capacity for blood and spinal fluid is $125-150 \mathrm{ml}$ [7]. Although much hutch has been made of the lack of a specific targeted therapy, much less is written about the success and goals of aggressive medical and surgical care for this disease like stroke. Current population based evidences recommend that maximum patients existing with stroke that are willingly survivable with good medical care. This suggests that excellent medical care likely has a potent, direct impact on stroke morbidity and mortality now, even before a specific therapy is found. Indeed, as discussed later, the overall aggressiveness of stroke care is directly related to the mortality from this disease [8]. The aim of the study was to assess the clinical status of the stroke patients attended in a tertiary care hospital of Bangladesh.

\section{METHODS}

This descriptive cross sectional study was conducted at the department of Medicine in Sheikh Hasina Medical College and Hospital, Jamalpur, Bangladesh during the period from January 2018 to December 2018. Non randomized, purposive sampling technique was applied for this study. As per the inclusion and exclusion criteria of this study inn total 180 stroke patients attended to the mentioned hospital were finalized as the sample and all the nurses engaged in the treatment procedure were associated in the study. Data was collected by using a semi structure, pre-tested and modified interviewer administered questionnaire. This intervention was approved by the ethical committee of the mentioned hospital. Proper written consents were taken from all the participants before starting the main part of intervention. Statistical package for social science (SPSS) version 20.0 (Chicago) a computer programmed was used to entry and analyze the collected data. Proportion was presented by frequency and cross tabulation analysis. The association was found out by using Pearson's chisquare $(\chi 2)$ test. 


\section{RESULT}

In this study $50.6 \%$ of the respondents belonged to more than 50 years age, followed by $26.2 \%$ belonged 46-55 years age group, $14.4 \%$ belonged to $36-$ 45 years age group, and $8.8 \%$ belonged to $25-35$ years age group with mean age 52.81 \pm 9.707 years. Most of the respondent $82 \%$ was male and rest $18 \%$ was female. Most of the respondents $(82 \%)$ of this study was married, followed by $9 \%$, was widow, $7 \%$ was unmarried, and only 2 was divorced of them. In total $62.3 \%$ of the respondents had 6-8 person family members, followed by $28.4 \%$ had $3-5$ person family members, and rest $9.3 \%$ had it was $9-12$ person family members. We found $60 \%$ of the respondents used tube well water, $37 \%$ used supply water, and rest $3 \%$ used boil water. Among the participants $40 \%$ respondents had tin shed house, followed by $27 \%$, had building, $17 \%$ had semi-building, and rest $16 \%$ had kacca house respectively whereas majority of the respondents (98\%) used sanitary latrine, and only $2 \%$ of them used nonsanitary latrine. In this study, out of all respondents $69.4 \%$ had family history of DM, followed by $30.6 \%$ did not have it. $96.7 \%$ had knowledge on stroke and rest $3.3 \%$ did not know about stroke. About the knowing the meaning of stroke, $92.9 \%$ of the respondents opined, followed by $79.2 \%, 44.3 \%$ and $30.6 \%$ it is cardiovascular disease, nerve disease and heart disease respectively. We found, $48.6 \%$ did not know about type of stroke, followed by $47.5 \%, 3.8 \%$ and $1.1 \%$ know it to be hemorrhagic, non-hemorrhagic, and ischemic respectively. In the type of treatment of stroke and which was $97.3 \%$ took medication, followed by, $67.8 \%$ took physiotherapy, $30.6 \%$ took surgery and, $8.2 \%$ took it others like Kabiraj, Fakir, Jhar-Fuk. In total $98.4 \%$ of the respondents investigated by blood test, followed by, $95.1 \%$ by ECG, $78.1 \%$ by CT scan, and $42.6 \%$ by MRI respectively. In total $44.3 \%$ respondents very suffering from HTN for 1-2 years, followed by $33.9 \%, 18.6 \%$, and $3.3 \%$ suffered for 3-5 years, 6-10 years, and more than 10 years respectively whereas $46.2 \%$ of the respondents very suffering from DM for 3-5 years, followed by $45.5 \%$ for $1-2$ years, and rest $8.3 \%$ for $6-10$ years. We observed, $60 \%$ of the respondents' duration of smoking was for 16-25 years, followed by $26 \%$ for 5-15 years, and $14 \%$ for $26-40$ years respectively. In this study among the respondents $24.6 \%$ got affected their right side, $23 \%$ left side and $20.2 \%$ both sides but $32.2 \%$ respondents could not get it diagnosed. In this study, majority of the respondents $(95 \%)$ family history of CVD was positive, and only 5\% family history of CVD was negative. There was the association between gender and knowledge on risk factor of stroke is DM. The association is strongly significant where the pvalue is 0.000 (which is less than .001).We found, $74.3 \%$ of the respondents very suffering from CVD for $1-5$ years, followed by $13.7 \%$ for $11-15$ years, $8.2 \%$ for 6-10 years, and rest $3.8 \%$ for more than 15 years. We found the association between gender and knowledge on risk factor of stroke is HTN. The association is significant where the $\mathrm{p}$-value is 0.007 (which is <.05).

Table-1: Age distribution of participants $(\mathrm{N}=180)$

\begin{tabular}{|l|l|l|}
\hline Age & n & \% \\
\hline 25-35 Years & 16 & 8.8 \\
\hline 36-45 Years & 26 & 14.4 \\
\hline 46-55 Years & 48 & 26.2 \\
\hline 56+ Years & 90 & 50.6 \\
\hline Total & 180 & 100 \\
\hline Mean \pm SD $=52.81 \pm 9.707$ & \\
\hline
\end{tabular}

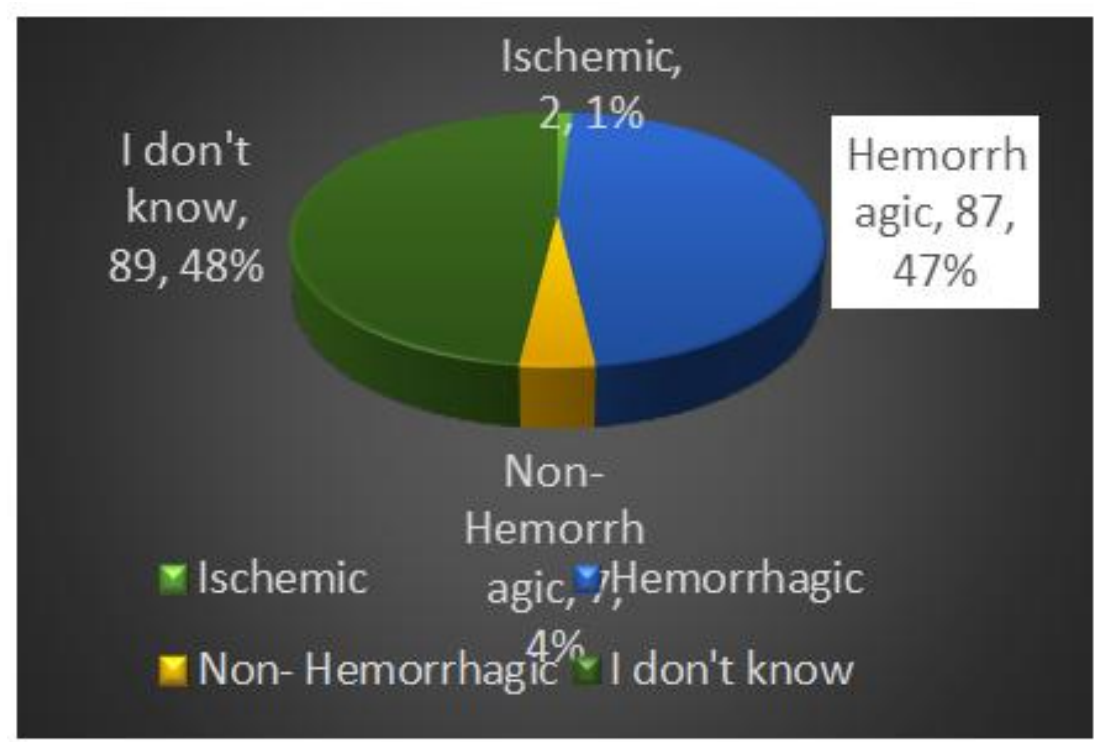

Fig-1: Distribution of the respondents by type of stroke $(\mathbf{n}=180)$ 


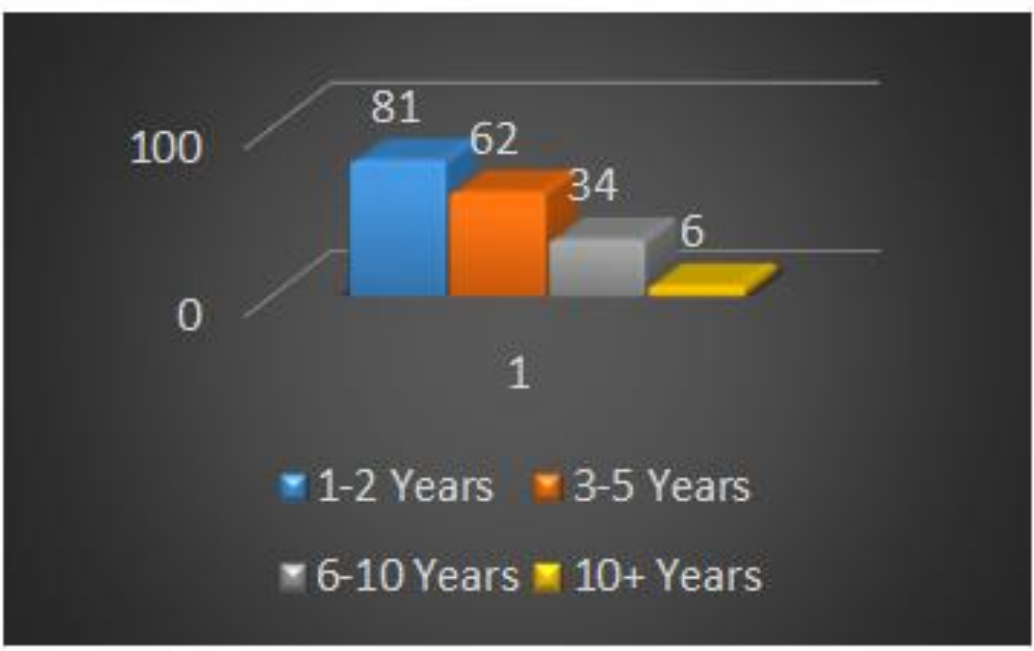

Fig-2: Distribution of the respondents by duration of suffering from HTN (n=180)

Table-2: Distribution of the respondents by family history of DM and knowledge on stroke (n=180)

\begin{tabular}{|l|l|l|l|}
\hline Variables & Answers & $\mathbf{n}$ & $\mathbf{\%}$ \\
\hline Family history of DM & Yes & 127 & 69.4 \\
\cline { 2 - 4 } & No & 56 & 30.6 \\
\hline \multirow{2}{*}{ Knowledge on Stroke } & Yes & 177 & 96.7 \\
\cline { 2 - 4 } & No & 6 & 3.3 \\
\hline
\end{tabular}

Table-3: Distribution of the respondents by meaning of stroke $(n=180)$

\begin{tabular}{|l|l|l|}
\hline Meaning of stroke & $\mathbf{n}$ & $\mathbf{\%}$ \\
\hline Cardiovascular disease & 145 & 79.2 \\
\hline Brain disease & 170 & 92.9 \\
\hline Nerve disease & 81 & 44.3 \\
\hline Heart disease & 56 & 30.6 \\
\hline
\end{tabular}

Table-4: Distribution of the respondents by affected side of stroke $(n=180)$

\begin{tabular}{|l|l|l|}
\hline Side involved & n & \% \\
\hline Right side of brain & 45 & 24.6 \\
\hline Left side of brain & 42 & 23 \\
\hline Both side of brain & 37 & 20.2 \\
\hline Not know & 59 & 32.2 \\
\hline Total & 180 & 100 \\
\hline
\end{tabular}

Table-5: Distribution of the respondents by knowledge on risk factors of stroke $(n=180)$

\begin{tabular}{|l|l|l|l|}
\hline Risk Factors & Answers & $\mathbf{n}$ & $\mathbf{\%}$ \\
\hline HTN & Yes & 180 & 100 \\
\hline \multirow{2}{*}{ DM } & Yes & 132 & 72.1 \\
\cline { 2 - 4 } & No & 51 & 27.9 \\
\hline \multirow{2}{*}{ Smoking } & Yes & 142 & 77.6 \\
\cline { 2 - 4 } & No & 41 & 22.4 \\
\hline \multirow{2}{*}{ Alcoholism } & Yes & 178 & 97.3 \\
\cline { 2 - 4 } & No & 6 & 2.7 \\
\hline
\end{tabular}

Table-6: Distribution of the respondents by HTN

\begin{tabular}{|l|l|l|l|l|l|}
\hline \multirow{2}{*}{ Risk factor } & Sex & Total & \multirow{2}{*}{ Chi-sq. } & \multirow{2}{*}{ p-val. } \\
\cline { 2 - 4 } & Male & Female & & & \\
\hline 1-2 Years & $59(32.2)$ & $22(12)$ & $81(44.3)$ & \multirow{2}{*}{12.026} & \multirow{2}{*}{0.007} \\
\hline 3-5 Years & $50(27.3)$ & $12(6.6)$ & $62(33.9)$ & & \\
\hline 6-10 Years & $27(14.8)$ & $7(3.8)$ & $34(18.6)$ & & \\
\hline 10+ Years & $5(2.7)$ & $1(0.5)$ & $6(3.3)$ & & \\
\hline Total & $140(77)$ & $40(23)$ & $180(100)$ & & \\
\hline
\end{tabular}


Table-7: Distribution of the respondents by DM

\begin{tabular}{|l|l|l|l|l|l|}
\hline \multirow{2}{*}{ Risk factor } & \multicolumn{2}{|l|}{ Sex } & Total & \multirow{2}{*}{ Chi-sq. } & p-val. \\
\cline { 2 - 4 } & Male & Female & & & \\
\hline 1-2 Years & $42(31.8)$ & $18(13.7)$ & $60(45.5)$ & 25.011 & 0 \\
\hline 3-5 Years & $49(37.2)$ & $12(9.0)$ & $61(46.2)$ & & \\
\hline 6-10 Years & $6(4.5)$ & $5(3.8)$ & $11(8.3)$ & & \\
\hline Total & $97(73.5)$ & $35(26.5)$ & $132(100)$ & & \\
\hline
\end{tabular}

\section{DISCUSSION}

The aim of this study was to assess the clinical status of the stroke patients attended in a tertiary care hospital of Bangladesh. Results found that out of all respondents $(69.4 \%)$ had family history of DM, followed by $30.6 \%$ did not have. Among them $96.7 \%$ had knowledge on stroke and rest $3.3 \%$ did not know about stroke. Among the respondents opined 92.9\%, followed by $79.2 \%, 44.3 \%$ and $30.6 \%$ opined it is cardiovascular disease, nerve disease and heart disease respectively. Findings reported that $48.6 \%$ did not know about type of stroke, followed by $47.5 \%, 3.8 \%$ and $1.1 \%$ was hemorrhagic, non-hemorrhagic, and ischemic respectively. The study was revealed that among the respondents $24.6 \%$ got affected their right side, in $23 \%$ left and $20.2 \%$ both side, but $32.2 \%$ respondents could not get it diagnosed. Study showed that $44.3 \%$ of the respondents suffered from HTN for 1-2 years, followed by $33.9 \%, 18.6 \%$, and $3.3 \%$ suffered for $3-5$ years, 6-10 years, and more than 10 years respectively. Study also showed that $46.2 \%$ of the respondents suffered from DM were for 3-5 years, followed by $45.5 \%$ for $1-2$ years, and rest $8.3 \%$ for $6-10$ years. Research results revealed that $60 \%$ of the respondents' duration of smoking was for $16-25$ years, followed by $26 \%$ for $5-15$ years, and $14 \%$ for $26-40$ years respectively. Among them most of the respondents $(95 \%)$ family history of CVD was positive, and only $5 \%$ family history of CVD was negative. Of them $74.3 \%$ of the respondents were suffering from CVD were for 1-5 years, followed by $13.7 \%$ for $11-15$ years, $8.2 \%$ for $6-10$ years, and rest $3.8 \%$ for more than 15 years. These results are greater than the results of the study on Inpatient costs, length of stay and mortality for cerebrovascular events in community hospitals conducted by Reed SD, 2001 [9]. Research found that $98.4 \%$ of the respondents investigated by blood test, followed by, $95.1 \%$ by ECG, $78.1 \%$ by CT scan, and $42.6 \%$ by MRI respectively. It was reported about the type of treatment of stroke and which was $97.3 \%$ took medication, followed by, $67.8 \%$ took physiotherapy, $30.6 \%$ took surgery and, $8.2 \%$ took it others like Kabiraj, Fakir, Jhar-Fuk. These findings are almost dissimilar to the study on Emerging medical and surgical management strategies in the evaluation and treatment of intracerebral hemorrhage conducted by Manno EM, 2005 [10]. Study found that $78.1 \%$ of the respondents obtained information about stroke from doctor, followed by $63.4 \%, 37.2 \%, 36.6 \%, 33.9 \%$, $19.1 \%$ and $13.7 \%$, from peer feedback, senior colleagues, newspaper, health education, TV and radio respectively. Research findings revealed the association between gender and knowledge on risk factor of stroke is HTN. The association is significant where the p-value is 0.007 (which is less than .05). It was also revealed the association between gender and knowledge on risk factor of stroke is DM. The association is strongly significant where the p-value is 0.000 (which is less than .001).

\section{Limitations of the study}

This was a single center study with small sample size. So the findings cannot be generalized due to selection bias.

\section{CONCLUSION}

Most of the respondents were not aware about consequence the bad effect of smoking which is a major risk factor of stroke. Stroke cases in Bangladesh have significantly increased in number over the past decades; adverse outcomes from these cases are also rising due to the low number of neurologists and specialized hospitals in the country. Because stroke poses long-term economic impacts on individuals, families, and the country; study findings urge the government to put more emphasis on healthcare development by building more stroke rehabilitation units and tertiary hospitals to prevent stroke occurrence and recurrence.

\section{RECOMMENDATIONS}

There is a need for repeated national prevalence estimates to further assess the stroke, management, treatment, and the including measures of other factors. Bangladesh government needs to emphasize healthcare development to cope with the increasing population density and to reduce stroke occurrence.

\section{REFERENCES}

1. Sanders MJ, McKenna K. Head and Facial Trauma. Mosby's Paramedic Textbook, 2nd revised Ed, Chapter 22, 2001. Available from: URL: http://research. omicsgroup.org /index. php/ Cerebral_contusion.

2. Roger VL, Gon AS, Mozaffar D. Heart disease and stroke statistics 2013 update: a report from the American Heart Association. PMID. 2013; 236 46. Available from: URL: http://circ.ahajournals.org /content/127/1/143.long.

3. Jain R, Deveikis J, Thompson BG. Management of patients with stunned myocardium associated with subarachnoid hemorrhage. American Journal of Neuroradiology, 2004; 25(1):126-29. Available 
from:

URL:

http://www.

ncbi.nlm.nih.gov/pubmed/14729541.

4. Zaroff JG, Rordorf GA, Ogilvy CS, Picard MH. Regional patterns of left ventricular systolic dysfunction after subarachnoid hemorrhage: Evidence for neurally mediated cardiac injury. Journal of the American Society of Echocardiography. 2000; 13(8):774-79. Available from: URL http:// www. onlineejase.com/article/S0894-7317 (00)831156/fulltext.

5. Foulkes MA, Wolf PA, Price RT, Mohr JP, Hier DB. The Stroke Data Bank: Design, methods, and baseline characteristics. Stroke. 1988; 19(5):54754. Available from: URL: http://www.ncbi.nlm.nih.gov/ pubmed/3363586.

6. Zahuranec DB, Gonzales NR, Brown DL, Lisabeth LD, Longwell PJ, Eden SV, Smith MA, Garcia NM, Hoff JT, Morgenstern LB. Presentation of intracerebral haemorrhage in a community. Journal of Neurology, Neurosurgery \& Psychiatry. 2006 Mar 1;77(3):340-4.
7. Hemphill JC, Newman J, Zhao S, Johnston SC. Hospital usage of early do-not-resuscitate orders and outcome after intracerebral hemorrhage. Stroke. 2004; 35:1130-34. Available from: URL: http://stroke.ahajournals.org/content/35/5/1130.ful 1.pdf+html.

8. Roach ES, Golomb MR, Adams R, Biller J, Daniels S, Deveber G, Ferriero D, Jones BV, Kirkham FJ, Scott RM, Smith ER. Management of stroke in infants and children: a scientific statement from a Special Writing Group of the American Heart Association Stroke Council and the Council on Cardiovascular Disease in the Young. Stroke. 2008 Sep 1;39(9):2644-91.

9. Reed SD, Blough DK, Meyer K, Jarvik JG. Inpatient costs, length of stay and mortality for cerebrovascular events in community hospitals. Neurology. 2001; 57:305-14.

10. Manno EM, Atkinson JLD, Fulgham JR, Wijdicks EFM. Emerging medical and surgical management strategies in the evaluation and treatment of intracerebral hemorrhage. Mayo Clin Proc. 2005; $80: 420-33$ 